\title{
Ectopic Sebaceous Glands over Buccal Mucosa: A Case Report on Fordyce Spot
}

\author{
Prajakta M Bapat ${ }^{1}$, Uma P Chaturvedi ${ }^{2}$, Sujaya Mazumder ${ }^{3}$, Raji Naidu ${ }^{4}$, Susan Cherian $^{5}$
}

\begin{abstract}
Aim and objective: To highlight the importance of histopathological diagnosis to identify Fordyce spots.

Background:These are normal variants in which sebaceous glands are ectopically located over the mucosal surfaces and are not in association with hair follicles. Fordyce spots, or Fordyce granules, can be found on the genital mucosa (glans penis and labia minor), esophagus, gastroesophageal junction, uterine cervix, sole of the foot, thymus, and tongue.

Case description: The following two cases are included in our case report:

(1) A 30-year-old male patient with a lesion of size $2 \mathrm{~mm}$ in diameter, located over right buccal mucosa. This was a painless white patch, clinically suggestive of lichen planus. This was histopathologically confirmed as Fordyce spots.

(2) This case was an incidental finding along with erythroplakic patch in a 60-year-old man.

Conclusion: Histopathology is the gold standard of diagnosis in this condition; it is imperative for the pathologist to identify the presence of Fordyce spots.

Clinical significance: Fordyce spots over the oral mucosa are reported rarely and is known to have an array of clinical mimics such as malignancies of oral mucosa.

Keywords: Ectopic sebaceous glands, Fordyce granules, Hereditary nonpolyposis colorectal cancer.

International Journal of Head and Neck Surgery (2021): 10.5005/jp-journals-10001-1444
\end{abstract}

\section{BACKGROUND}

Fordyce spots was first described in 1896, by Fordyce as whitish spots symmetrically located on the vermilion border of the lips, oral mucosa, and, rarely, genital mucosa. It was therefore named as Fordyce spot based on his name. ${ }^{1}$ These are normal variants in which sebaceous glands are ectopically located over the mucosal surfaces and are not in association with hair follicles. ${ }^{2}$ Fordyce spots, or Fordyce granules, can be found on the genital mucosa (glans penis and labia minor), esophagus, gastroesophageal junction, uterine cervix, sole of the foot, thymus, and tongue. ${ }^{3}$ They appear as yellowish-white spots so also called as milk spots. ${ }^{3}$ Ectopic sebaceous glands are a developmental abnormality. ${ }^{2}$ The incidence increases with age, being more common in adults than in children. ${ }^{1}$ Male to female ratio is 2:1, as the granules are the target of androgenic hormones and receptors in dermal sebaceous glands. ${ }^{4}$

\section{Case Description}

A 30-year-old man presented to ENT outpatient department (OPD) of BARC Hospital, Anushakti Nagar, with cyst over buccal mucosa, since 3 months. He had no history of pain, discharge, fever, foreign body sensation, and bleeding from the site. Oral examination disclosed hypopigmented maculopapular spots over right side of the buccal mucosa which were closely grouped and asymptomatic, $2 \mathrm{~mm}$ in diameter. Other areas in buccal mucosa were normal. Patient did not report any systemic abnormality. Clinical impression was suggestive of lichen planus.

Histopathology of the lesions revealed thickened and hyperkeratotic epithelium, with numerous underlying sebaceous glands with mature sebaceous lobules. Glands were not in association with hair follicles (Fig. 1). Deeper tissue showed adipose
${ }^{1-5}$ Department of Pathology, Bhabha Atomic Research Center Hospital, Mumbai, Maharashtra, India

Corresponding Author: Prajakta M Bapat, Department of Pathology, Bhabha Atomic Research Center Hospital, Mumbai, Maharashtra, India, Phone: +91 7620122166, e-mail: drprajaktack@gmail.com

How to cite this article: Bapat PM, Chaturvedi UP, Mazumder S, et al. Ectopic Sebaceous Glands over Buccal Mucosa: A Case Report on Fordyce Spot. Int J Head Neck Surg 2021;12(3):119-120.

Source of support: Nil

Conflict of interest: None

tissue, mucous salivary glands, and ducts. ${ }^{3}$ No atypia reported on histopathology. So final impression was given as ectopic sebaceous gland with hyperplastic epithelium suggestive of Fordyce glands. Second case was of a 61-year-old man who presented to ENT OPD with burning sensation of buccal mucosa for 5 to 6 months. After oral examination final clinical diagnosis was given as erythroplakic patch, which was confirmed by histopathology. In this case, we found normal and thinned out mucosa with underlying dilated congested blood vessels with the presence of normal sebaceous glands which are not associated with hair follicles and was thus also reported as Fordyce granules on histopathology (Fig. 2).

\section{Discussion}

Fordyce spots or Fordyce granules are ectopic sebaceous glands which are histologically normal. Fordyce's spot consists of a single sebaceous lobule or gland located in the dermis or submucosa. ${ }^{5}$ The ducts of the gland directly opens over mucosal surface. The lesion is seen in both men and women but more 


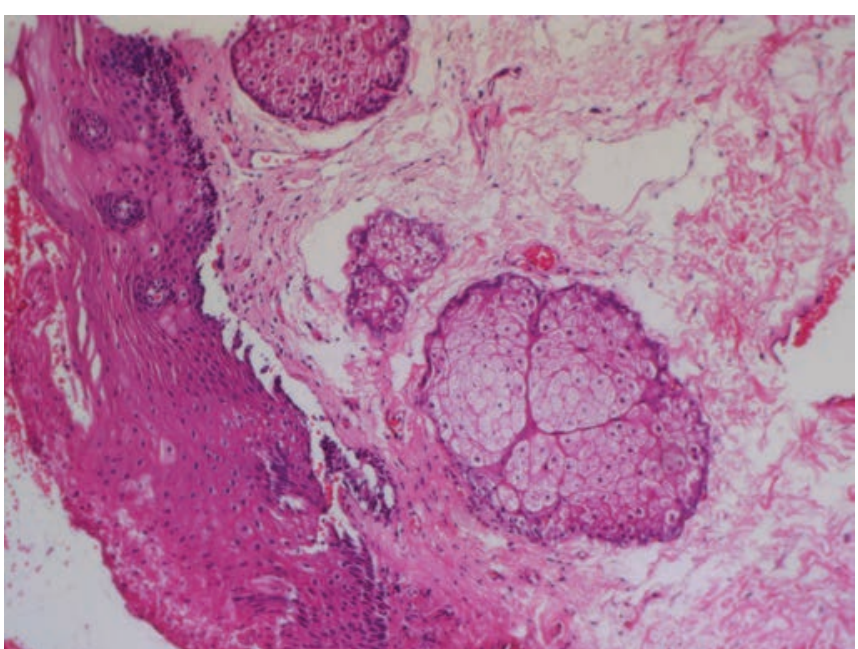

Fig. 1: Photomicrograph of sections from the lip mucosa showing, hyperkeratotic epithelium with underlying ectopic sebaceous glands not associated with hair follicles (H\&E x10)

prominent in men as it is associated with androgenic hormones. Many other clinical conditions can mimic Fordyce spots such as milia, sebaceous hyperplasia, syringomas, molluscum contagiosum, lichen nitidus, closed comedones, cutaneous myxomas, and calcinosis cutis and therefore histopathology is the key to diagnosis. 'They are commonly located over vermilion border of lips, buccal mucosa, forehead, and also can be seen over esophageal mucosa, and genital mucosa. ${ }^{3}$

Montgomery and Hay examined two cases microscopically and found large number of apparently normal sebaceous glands underlying the yellowish area. They concluded that subepidermal collection of fatty matter contained in these glands leads to yellowish white discoloration of lesion. ${ }^{5}$

We reported two cases, one was a 30 -year-old male patient. Lesion was located over right buccal mucosa of size $2 \mathrm{~mm}$ in diameter. This was a painless white patch, clinically suggestive of lichen planus. This was histopathologically confirmed as Fordyce spots (Figs 1 and 2).

Second case was an incidental finding along with erythroplakic patch in a 60-year-old man. Significance of these condition is for two reasons: one is its rare association with facial hypopigmentation and the second is its unilateral distribution. ${ }^{3}$ Another interesting fact is that it has been reported that following activation of the hedgehog pathway, the number and size of sebaceous gland increase. ${ }^{6}$ As this pathway has multiple roles in development and progression of many cancers, it is important to confirm the presence of Fordyce spots on histopathology. ${ }^{6}$ Fordyce spots and alteration in vascular patterns have also been noted in oral manifestations of hereditary nonpolyposis colorectal cancer (HNPCC). ${ }^{6}$ As it has been proposed that Fordyce spots can be associated with systemic disease, thorough clinical examination and histopathological confirmation could be helpful to increase the rate of HNPCC diagnosis in affected families.

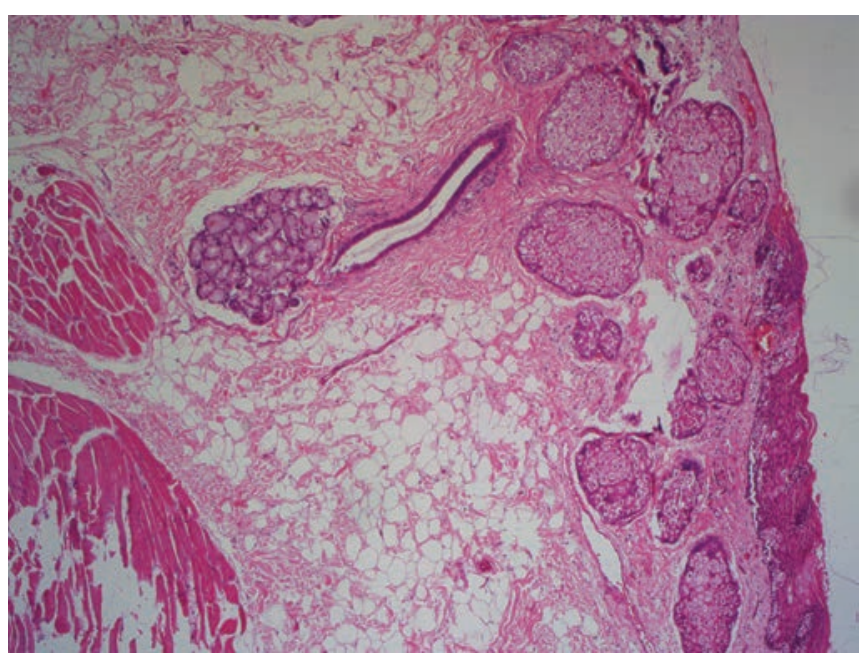

Fig. 2: Photomicrograph of sections from cheek mucosa showing ectopic sebaceous glands associated with erythroplakia (H\&E x10)

Treatment is usually not necessary as the condition is benign in nature. Treatment is desired only for cosmetic reasons. Treatment options available at present are micro-punch surgery, electrodesiccation, cryotherapy, ablative laser, photodynamic therapy, topical bichloracetic acid, topical tretinoin, and oral isotretinoin.

\section{Clinical Sgnificance}

Fordyce spots over the oral mucosa are reported rarely and is known to have an array of clinical mimics. Also, its recent association with HNPCC further highlights the importance of diagnosing it. As histopathology is the gold standard of diagnosis in this condition it is imperative for the pathologist to identify the presence of Fordyce spots.

\section{References}

1. Fordyce JA. A peculiar affection of the mucous membrane of the lips and oral cavity. J Cutan Dis 1896;14:413-419. DOI: 10.1001/archderm.1996.03890350023003

2. Braun-Falco O, Plewig G, Wolff $\mathrm{HH}$, et al. Diseases of the lips and oral mucosa. In Dermatology (pp. 1164-1165). Berlin, Heidelberg: Springer; 2000. DOI: 10.1007/978-3-642-97931-6_33

3. Mattoo KA, Singh M, Gupta S. Fordyce granules associated with hypopigmentation of facial skin. Oral Surg, Oral Med, Oral Radiol 2014;2:23-24. DOI: 10.1007/978-3-642-97931-6_33

4. Baeder FM, Pelino JE, De Almeida ER, et al. High-power diode laser use on Fordyce granule excision: a case report. J Cosmet Dermatol 2010;9(4):321-324. DOI: 10.1111/j.1473-2165.2010.00531.x

5. Hoque T, Islam AM. Fordyce's disease treated with pimacrolimus: a rare case report. Anwer Khan Modern Med Coll J 2018;9(2):148-151. DOI: 10.3329/akmmcj.v9i2.39212

6. Almeida FT, Gomes RR, Leite AF, et al. Oral manifestations of hereditary nonpolyposis colorectal cancer syndrome: a family case series. J Med Case Rep 2014;8(1):1-6. DOI: 10.1186/1752-1947-8-249 